\title{
Plasma Catecholamines During Activation of the Sympathetic Nervous System in a Patient with Shy-Drager Syndrome
}

\author{
G. Gross ${ }^{1 *}$, M. Nagel-Hiemke ${ }^{1}$, and K.-H. Krause ${ }^{2}$ \\ ${ }^{1}$ Pharmakologisches Institut des Universitäts-Klinikums, Hufelandstr. 55, D-4300 Essen \\ ${ }^{2}$ Neurologische Universitätsklinik, Voßstr. 2, D-6900 Heidelberg, Federal Republic of Germany
}

\begin{abstract}
Summary. Plasma catecholamines and circulation parameters were studied in a patient with a Shy-Drager syndrome. Basal values of free noradrenaline and dopamine were within the normal range, whereas the adrenaline level was decreased. The response of plasma catecholamines to different kinds of physical activity was pathological. The inability to maintain elevated catecholamine levels during prolonged activity corresponded to impaired circulatory regulation and may provide an additional tool for diagnosis and monitoring of the Shy-Drager syndrome.
\end{abstract}

Key words: Shy-Drager syndrome - Idiopathic orthostatic hypotension Plasma catecholamines - Circulatory regulation.

Zusammenfassung. Bei einer Patientin mit Shy-Drager-Syndrom wurden Plasmakatecholamine und Kreislaufparameter untersucht. Die basalen Werte an freiem Noradrenalin und Dopamin waren im Normbereich, Adrenalin erniedrigt. Die Reaktion der Plasmakatecholamine auf verschiedene Arten körperlicher Belastung war deutlich pathologisch. Die Unfähigkeit, die Plasmakatecholamine vor allem während längerer Aktivität auf erhöhtem Niveau zu halten, entsprach der beeinträchtigten Kreislaufregulation und kann als weiteres diagnostisches Kriterium angesehen werden.

\section{Introduction}

The Shy-Drager syndrome (Shy and Drager 1960) is characterized by autonomic dysfunction, e.g. orthostatic hypotension, anhidrosis, urinary and fecal incontin-

* Corresponding author 
ence, accompanied by additional neurological symptoms. According to different patterns of degeneration, Bannister and Oppenheimer (1972) described two subtypes, one associated with olivopontocerebellar or striatal degeneration, the other with idiopathic parkinsonism including typical Lewy bodies. One common feature of this multisystem degenerative process seems to be a nerve cell loss in the intermediolateral column of the spinal cord as well as in pigmented areas of the brain. The main symptom of this disease, the orthostatic hypotension without a compensatory elevation of the heart rate, may be explained by the lesion of preganglionic sympathetic cells and a subsequent decrease in catecholamine release from postganglionic fibers.

Our present knowledge of catecholamine release and metabolism in the ShyDrager syndrome is mainly derived from investigations of urinary excretion or levels in the cerebrospinal fluid. Several authors (Luft and Euler 1953; Goodall et al. 1967; Hedeland et al. 1969; Anlauf et al. 1975) reported a decreased urinary output of catecholamines. Routine assays, however, of ten fail to detect a reduction of urinary catecholamines (Sharpe et al. 1972; Thapedi et al. 1971). Since plasma catecholamines may be a better index for an altered secretion rate we tested plasma catecholamines of a patient with a well documented Shy-Drager syndrome before and after stimulation of the sympathetic nervous system by postural change and physical activity. The tests were performed during and after cessation of l-Dopa/ benserazide medication, which was given to alleviate Parkinson symptoms.

\section{Methods}

Blood pressure was measured according to Riva-Rocci. Blood samples were taken from the cubital vein. Catecholamines were determined radioenzymatically using a modification of the method of Peuler and Johnson as described by Nagel and Schümann (1980). Urinary catecholamines were measured with a fluorometric assay (Palmer, J. P. 1964).

\section{Case Report}

The patient, a 54-year-old woman, was first admitted to hospital in 1974 with a history of orthostatic hypotension for 4 years. The first signs were occasional syncopal episodes, which gradually became more frequent and severe. She felt transiently dizzy, noted blurred vision or became unconscious. These attacks seemed to be related to changes in posture and effort. At that time tilting resulted in a marked fall of blood pressure without a remarkable increase in heart rate. The Vasalva maneuver was not followed by the typical increase in mean blood pressure and bradycardia. The urinary catecholamine excretion was in the normal range. Anhidrosis was first noted in 1974, constipation and urinary incontinence during the following year. A Parkinson syndrome developed in 1976. Loss of facial mobility was followed by bradykinesis, retro- and lateropulsion and dysarthria. During the last 2 years she complained of occasional diplopia and dysphagia. Her gait had become unsteady and she could walk only about $500 \mathrm{~m}$ without postural faintness.

Several treatments proved unavailing or caused little improvement. The mineral corticoid 9$a$-fluorocortisol and sympathomimetic drugs like norfenefrine, etilephrine and dihydroergotamine had no clear effect. Administration of the MAO-inhibitor tranylcypromine combined with tyramine-rich food resulted in temporary relief. A l-Dopa/benserazide combination (Madopar) in a moderate dose $(3 \times 125 \mathrm{mg})$ was given, when the Parkinson syndrome developed and continued until the last admission. 


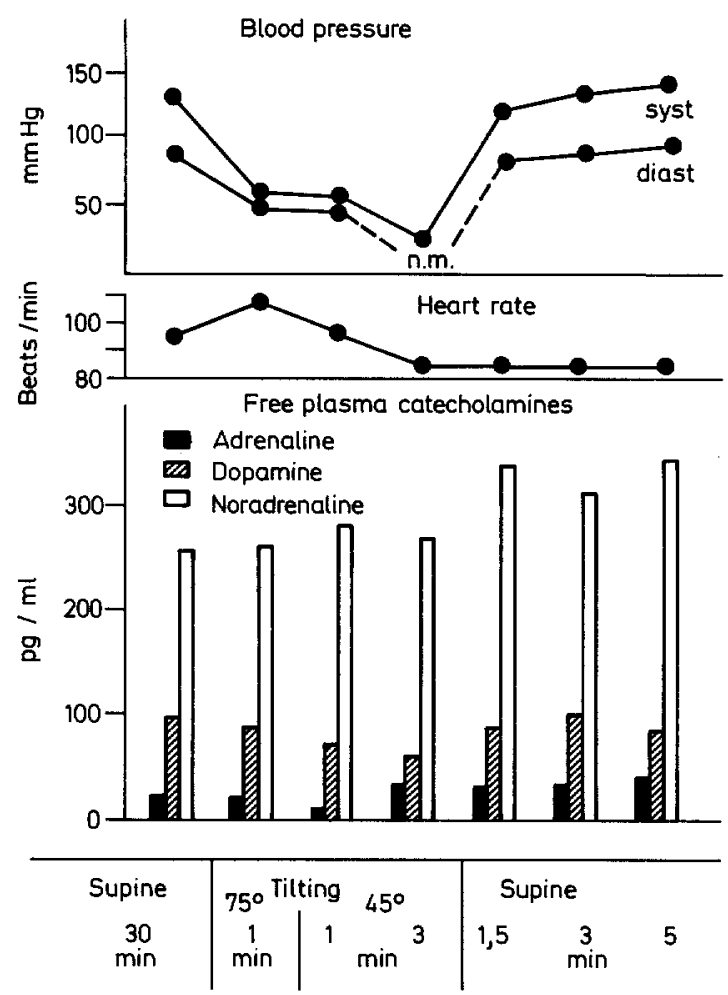

Fig. 1. Circulation parameters and plasma catecholamines of patient with Shy-Drager syndrome at rest and during tilting. n.m. - not measurable

On examination her intellectual function was normal. A paucity of facial expression was noted, the voice was slurred, all movements bradykinetic, the gait small stepped with retro- and lateropulsion. She reported occasional diplopia on left gaze. The pupils were equal, slowly reacting to light and accomodation. Slight ptosis was found on the left side. No iris atrophy was detected. Power was normal throughout but there was considerable rigidity of the neck muscles, moderate rigidity of all limbs, more distinct on the left. The muscles of the hands and forearms seemed to be atrophied. The reflexes were symmetrically brisk but no pyramidal signs were noted. All modalities of sensation were normal. EEG, skull radiograph and CT revealed no pathological signs.

\section{Results}

Blood pressure, heart rate and plasma catecholamine concentrations at rest, after changing the body posture, and during physical activity are presented in Figures 1 and 2. After a rest period of $30 \mathrm{~min}$ in the supine position the values for blood pressure and heart rate were normal. Postural change and different degrees of physical activity, however, resulted in low or even immeasurable pressure values. In spite of the marked fall of systolic and diastolic blood pressure, the heart rate showed only a moderate reflex acceleration and declined to basal values during 


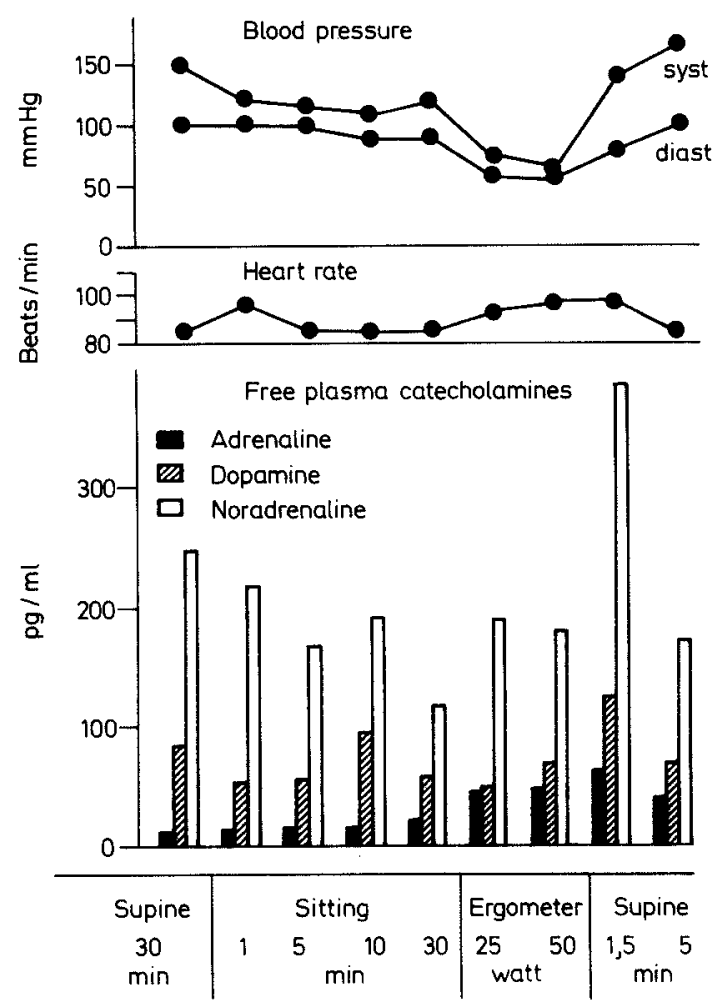

Fig. 2. Circulation parameters and plasma catecholamines of patient with Shy-Drager syndrome at rest and during ergometer training

sustained tilting. The patient nearly fainted after $1 \mathrm{~min}$ of $75^{\circ}$ and $3 \mathrm{~min}$ of $45^{\circ}$ of tilt. Levels of free plasma catecholamines at rest amonted to about $250 \mathrm{pg} / \mathrm{ml}$ for noradrenaline, $12-22 \mathrm{pg} / \mathrm{ml}$ for adrenaline and to $83-94 \mathrm{pg} / \mathrm{ml}$ for dopamine. Compared with values from healthy volunteers (Table 1), and those reported in the literature (Van Loon et al. 1979), only the basal adrenaline level of our patient seemed to be lowered. Basal plasma noradrenaline and dopamine concentrations were within the normal range. During prolonged tilting, which is known to be a strong stimulus for sympathetic regulation in healthy subjects (Lake et al. 1976; Watson et al. 1979), the noradrenaline level remained stable, although the patient nearly fainted. Free adrenaline remained subnormal or even decreased $(9-28 \mathrm{pg} / \mathrm{ml})$; the same held true for dopamine. Similar reactions were observed following less powerfull stimuli for adrenergic regulation such as sitting or bicycle ergometer training (Fig. 2). In the sitting position and during ergometer training, noradrenaline and dopamine plasma levels again failed to rise or even declined. Only the adrenaline concentration increased slightly. After return to the recumbent position an excess of noradrenaline concentration was found. Therapy with moderate doses of 1-Dopa ( $300 \mathrm{mg} /$ day) combined with benserazide ( $75 \mathrm{mg} /$ day) did not improve circulation parameters nor change the reaction of plasma noradrenaline and adrenaline to physical stress (Table 2). Ergometer training 
Table 1. Free plasma catecholamine levels of healthy persons at rest and during physical activity

\begin{tabular}{lllr}
\hline & Noradrenaline & $\begin{array}{l}\text { Adrenaline } \\
(\mathrm{pg} / \mathrm{ml})\end{array}$ & Dopamine \\
\hline Rest & $196 \pm 35$ & $64 \pm 10$ & $84 \pm 31$ \\
50 Watt & $370 \pm 75$ & $87 \pm 7$ & $175 \pm 78$ \\
\hline
\end{tabular}

$N=5-8$

Given are means \pm S.E.M. of free catecholamines

Table 2. Effect of 1-Dopa/benserazide therapy on circulation parameters and free plasma catecholamines in a patient with Shy-Drager syndrome

\begin{tabular}{llclllc}
\hline & & $\begin{array}{l}\text { Blood } \\
\text { pressure } \\
\text { (mm Hg) }\end{array}$ & $\begin{array}{l}\text { Heart rate } \\
\text { (beats/min) }\end{array}$ & $\begin{array}{l}\text { Nor- } \\
\text { adrenaline } \\
(\mathrm{pg} / \mathrm{ml})\end{array}$ & $\begin{array}{l}\text { Adrenaline } \\
(\mathrm{pg} / \mathrm{ml})\end{array}$ & $\begin{array}{c}\text { Dopamine } \\
(\mathrm{pg} / \mathrm{ml})\end{array}$ \\
\hline Without & Rest (supine) & $150 / 100$ & 84 & 246 & 12 & 83 \\
therapy & Ergometer (50 Watt) & $60 / 55$ & 96 & 178 & 47 & 68 \\
& Rest (supine) & $130 / 90$ & 96 & 255 & 22 & 94 \\
& Tilting & $25 /-$ & 84 & 268 & 28 & 61 \\
\hline 1-Dopa/ & Rest (supine) & $120 / 90$ & 84 & 280 & 12 & 736 \\
benserazide & Ergometer (50 Watt) & $60 / 55$ & 84 & 148 & 45 & 360 \\
& Rest (supine) & $110 / 90$ & 84 & 207 & 10 & 952 \\
& Tilting & not & 84 & 183 & 24 & 658 \\
& & measurable & & & & \\
\hline
\end{tabular}

( 50 watt) or tilting $\left(45^{\circ}\right.$ ) resulted in a decrease in blood pressure to about the same extent as observed without this therapy. The elevated dopamine values indicated that the peripheral Dopa decarboxylase was only partially inhibited by benserazide. Urinary $24 \mathrm{~h}$ excretion of total catecholamines was within the normal range $(11 \mu \mathrm{g} / 24 \mathrm{~h})$ without therapy.

\section{Discussion}

The clinical features evident in our patient conform to the diagnosis of the ShyDrager syndrome. They include pronounced orthostatic hypotension, urinary incontinence, loss of sweating and extrapyramidal signs. A final classification according to Graham and Oppenheimer (1972) and Vanderhaegen (1970), who described two subtypes of this disease, was not possible. Some clinical signs, such as transient diplopia and dysphagia, indicate that other systems than the sympathetic and the nigrostriatal may also be affected. However, no signs of olivopontocerebellar atrophy were noted.

Postural hypotension was the most prominent and incapacitating symptom in our case. All kinds of physical stress, including ergometer training, tilting, and even 
sitting, resulted in a marked fall of systolic and diastolic blood pressure. The reflex increase in heart rate, mediated by sympathetic nerves, which is the normal response in healthy subjects or in other kinds of hypotension, was almost completely lacking. The highest increase in heart rate-from 94 to 108 beats $/ \mathrm{min}$, observed during tilting - was insufficient to compensate for the fall of blood pressure. Blood pressure values at rest (130-150/80-100 $\mathrm{mm} \mathrm{Hg}$ ) were in agreement with normal values of free plasma noradrenaline. The concentration of this neurohormone was apparently sufficient to maintain the tone of resistant vessels in the supine position.

This fact may be responsible for the poor diagnostic value of routine fluorometric determinations of urinary catecholamines in the Shy-Drager syndrome. As in our case the daily excretion of total catecholamines was repeatedly found to be normal (Sharpe et al. 1972; Thapedi et al. 1971). In contrast to our results, Bannister et al. (1977) reported decreased basal plasma levels for noradrenaline in the Shy-Drager syndrome. The autonomic failure of their patients might have been more severe. Our data demonstrate that the determination of the basal noradrenaline level is not sufficient to support the diagnosis of a Shy-Drager syndrome. The basal secretion rate of the adrenal medulla, however, was impaired in our patient, since adrenaline levels at rest were subnormal. Basal dopamine concentrations without 1-Dopa therapy remained unaltered by the disease. Postural change and physical activity normally stimulate the sympathetic nervous system and thus raise plasma catecholamine levels, especially when this stimulation is prolonged (Lake et al. 1976; Watson et al. 1979; Van Loon et al. 1979). The rather tight coupling of plasma catecholamines to different degrees of physical activity was loosened in our patient. The most prominent deviation from normal conditions, which has to be clearly considered as pathological, was the failure to raise plasma noradrenaline. It was apparent in all tests. Instead even a decline of plasma noradrenaline was observed during prolonged bicycling. The increase in plasma noradrenaline concentration after regaining the recumbent position (Fig. 2) was presumably caused by the reflux and remixing of blood from the venous pool. Our findings described above are in agreement with and support neuropathological studies which describe a loss of preganglionic sympathetic cells in the intermediolateral column of the spinal cord. According to our results, the best parameter which can be used as a diagnostic tool, and for monitoring the progress of autonomic failure in the Shy-Drager syndrome, is the relation of basal free plasma catecholamine, especially noradrenaline, concentrations to those during prolonged activity. Moderate doses of 1-Dopa/benserazide did not improve circulation parameters and the response of plasma catecholamines to the different stimuli, although Dopa decarboxylase was not completely inhibited and dopamine levels accordingly increased.

\section{References}

Anlauf M, Werner U, Merguet P, Graben N, Bock KD (1975) Klinisch-experimentelle Untersuchungen bei Patienten mit asympathikotoner Hypotonie. Dtsch med Wschr 100:924-933

Bannister R, Oppenheimer DR (1972) Degenerative diseases of the nervous system associated with autonomic failure. Brain $95: 457-474$ 
Bannister R, Sever P, Gross M (1977) Cardiovascular reflexes and biochemical responses in progressive autonomic failure. Brain 100:327-344

Goodall McC, Harlam WR Jr, Alton BS (1967) Noradrenaline release and metabolism in orthostatic (postural) hypotension. Circulation 36:489-496

Hedeland H, Dymling J-F, Hökfelt B (1969) Catecholamines, renin and aldosterone in postural hypotension. Acta Endocrinol 62:411-424

Lake CR, Ziegler MG, Kopin IJ (1976) Use of plasma norepinephrine for evaluation of sympathetic neuronal function in man. Life Sciences 18:1315-1326

Luft R, von Euler US (1953) Two cases of postural hypotension showing a deficiency in release of norepinephrine and epinephrine. J Clin Invest 32:1065-1069

Nagel M, Schümann HJ (in press) A sensitive method for determination of conjugated catecholamines in blood plasma. J Clin Chem Clin Biochem

Palmer JF (1964) The use of $\beta$-thiopropionic acid for the analysis of mixtures of adrenaline and noradrenaline in plasma by the fluorometric trihydroxyindole method. W I Med J 13:38-53

Sharpe J, Marquez-Julio A, Ashby P (1972) Idiopathic orthostatic hypotension treated with levodopa and MAO inhibitor: a preliminary report. Can Med Ass J 107:296-300

Shy GH, Drager GA (1960) A neurological syndrome associated with orthostatic hypotension. A clinical-pathologic study. Arch Neurol 2:511-527

Thapedi JM, Ashenhurst EM, Rozdilsky B (1971) Shy-Drager syndrome. Report of an autopsied case. Neurology $21: 26-32$

Vanderhaegen J-J, Prérier O, Sternon JE (1970) Pathological findings in idiopathic orthostatic hypotension. Its relationship with Parkinson's disease. Arch Neurol 22:207-214

Van Loon GR, Schwark L, Sole MJ (1979) Plasma dopamine responses to standing and exercise in man. Life Sciences 24:2273-2278

Watson RDS, Hamilton CA, Reid JL, Littler WA (1979) Changes in plasma norepinephrine, blood pressure and heart rate during physical activity in hypertensive man. Hypertension 1: $341-346$

Received June 21, 1980 